\title{
A Middle-Aged Man Presented with Quadriparesis during COVID-19 Pandemic
}

\author{
Forhad Uddin Hasan Chowdhury ${ }^{a}$ Shrebash Paul ${ }^{b}$ Sakib Aman ${ }^{a}$ \\ Ashraful Haque $^{c}$ Md Rafiquzzaman $^{d}$ Mujibur Rahman ${ }^{b}$ \\ Fazle Rabbi Chowdhury, e \\ aDepartment of Medicine, Dhaka Medical College Hospital, Dhaka, Bangladesh; \\ ${ }^{b}$ Department of Internal Medicine, Bangabandhu Sheikh Mujib Medical University, Dhaka, \\ Bangladesh; 'Department of Blood Transfusion, Sheikh Hasina National Institute of Burn \\ and Plastic Surgery, Dhaka, Bangladesh; ${ }^{\mathrm{d} D e p a r t m e n t}$ of Endocrinology, Dhaka Medical \\ College Hospital, Dhaka, Bangladesh; ${ }^{\mathrm{A}}$ Mahidol-Oxford Tropical Medicine Research Unit \\ (MORU), Bangkok, Thailand
}

\section{Keywords}

Guillain-Barré syndrome · COVID-19 - Reverse transcriptase-polymerase chain reaction .

Bangladesh $\cdot$ Limb weakness

\section{Abstract}

The clinical presentation of COVID-19 is varied: from asymptomatic to severe neurological syndrome like stroke can happen. Guillain-Barré syndrome (GBS) as a manifestation of COVID-19 is not very common. GBS is an acute immune-mediated polyradiculoneuropathy that usually occurs following previous exposure to infection. Here, we are reporting a case of GBS related to COVID-19 infection. The reported case presented with quadriparesis and was diagnosed with GBS after evaluation. At the same time, his RT-PCR for COVID-19 was also positive. Interestingly, this patient suffered from COVID-19 2 months before this presentation. He was successfully treated with intravenous immunoglobulin. The clinician should be aware of severe neurological complications such as GBS as a potentially life-threatening complication related to COVID-19.

\section{Karger ${ }^{\prime \prime}=$}


Chowdhury et al.: COVID-19 Infection Presented as Quadriparesis

\section{Introduction}

Since the first series of patients were reported in Wuhan, China, in December 2019, the numbers of COVID-19 patients are increasing day by day. In Bangladesh, the first case of COVID-19 was detected on March 8, 2020. Since then, in early September 2020 (while this case was diagnosed), the total number of reported cases in Bangladesh was 321,615, and until today, the number had reached to almost 8 million [1]. Initially, COVID-19 patients typically presented with a pneumonia-like presentation [2]. However, with time, the spectrum of involvement of different body systems by COVID-19 is being explored. Amongst them, neurological involvements are increasingly common and being reported frequently. The neurological presentation includes weakness, headache, dizziness, muscle pain, confusional state, loss of taste and smell, stroke, and meningoencephalitis. Approximately half of the patients experience some neurological manifestations [3-5]. Guillain-Barre syndrome (GBS) is an immune-mediated peripheral neuropathy. In about two-thirds of cases, respiratory and digestive tract infection precedes the autoimmune demyelination process of peripheral nerves, which is clinically manifested by the ascending pattern of limb weakness, cranial nerve involvement, and sometimes autonomic disturbances [6]. As of now, only a few cases of GBS following COVID-19 infection have been published [7, 8]. Here, we are reporting a middle-aged man who presented with quadriparesis and was later confirmed as a case of GBS following SARS-CoV-2 infection.

\section{Case Presentation}

A 50-year-old banker was admitted to Dhaka Medical College Hospital (DMCH), Bangladesh, on September 5, 2020, with complaints of weakness of all 4 limbs. He had no comorbid conditions. Two months prior to this admission, the patient had suffered from severe COVID-19 infection (RT-PCR positive). He was treated in a tertiary care hospital with high-flow oxygen (maximum $30 \mathrm{~L}$ ), steroid (dexamethasone for 10 days), enoxaparin (12 hourly for 7 days), and antibiotics. He completely recovered and became RT-PCR negative and therefore discharged from the hospital on July 21, 2020. At home, he had been doing well, performing all household activities and resumed his job. At the end of August 2020, he developed weakness of both lower limbs, which gradually progressed and involved both upper limbs. There was no history of newonset respiratory tract infection, gastrointestinal tract infection, or recent vaccination after the recovery from the first episode of COVID-19, which possibly ruled out the other causes of GBS. On admission, his muscle powers of both lower limbs were $3 / 5$ and his upper limbs $2 / 5$. There was hypotonia of limb muscles. Deep tendon reflexes of all 4 limbs were absent along with the absent plantar response (bilaterally). All modalities of sensation were intact. There were no bowel or bladder difficulties, cranial nerve involvement, and respiratory distress. Within $48 \mathrm{~h}$ of admission, his limb weaknesses worsened, and muscle power of lower limbs reduced to $2 / 5$ and upper limbs to $1 / 5$. The patient was tested for COVID-19 by RT-PCR from a nasopharyngeal swab before physiotherapy and found positive. Nerve conduction study revealed acute inflammatory demyelinating polyneuropathy (Fig. 1), and CSF showed albumin-cytological dissociation with a CSF protein content of $0.93 \mathrm{~g} / \mathrm{L}$. However, CSF RT-PCR for SARS-CoV- 2 was negative. However, both IgM and IgG COVID-19 antibodies were found positive (Table 1). An intravenous immunoglobulin (IVIG) cycle at $0.4 \mathrm{~g} / \mathrm{kg} /$ day was started immediately and given over 5 days, leading to a significant improvement of the weakness. He did not receive any other specific therapy (steroid, antiviral, or other immunosuppressive) for COVID as there were no relevant symptoms. Within 2 weeks, the patient completely recovered. The timeline of the major events is described in Figure 2.

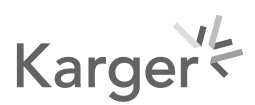




\begin{tabular}{|c|c|c|c|c|c|c|c|c|}
\hline Site & $\begin{array}{c}\begin{array}{c}\text { Latency } \\
\text { (ms) }\end{array} \\
\end{array}$ & Amplitude & Aren & Segment & \begin{tabular}{|c|}
$\begin{array}{c}\text { Ditancen } \\
(\mathrm{mm})\end{array}$ \\
\end{tabular} & $\begin{array}{c}\text { Interval } \\
\text { (ms) }\end{array}$ & $\begin{array}{l}\mathrm{NCV} \\
(\mathrm{m} / \mathrm{s}) \\
\end{array}$ & NCVN.D. \\
\hline \multicolumn{9}{|l|}{ Peroneal, L } \\
\hline Ankle & $13.86 \mathrm{~m}$ & $440.0 \mathrm{uV}$ & $1.775 \mathrm{mVm}$ & Ankle - Fibneck & $300 \mathrm{~mm}$ & $11.58 \mathrm{~ms}$ & $25.9 \mathrm{~m} / \mathrm{s}$ & \\
\hline Fibneck & $25.44 \mathrm{~m}$ & $340.0 \mathrm{uV}$ & $2.391 \mathrm{mVm}$ & Fibneck - Fibneck & $70 \mathrm{~mm}$ & $1.86 \mathrm{~ms}$ & $37.6 \mathrm{~m} / \mathrm{s}$ & \\
\hline Fibneck & $27.30 \mathrm{~m}$ & $250.0 \mathrm{uV}$ & $2.113 \mathrm{mVm}$ & & & & & \\
\hline \multicolumn{9}{|l|}{ Tibial, L } \\
\hline Ankle & $7.82 \mathrm{~ms}$ & $3.910 \mathrm{mV}$ & $12.35 \mathrm{mVm}$ & Anklc - Popfossa & $390 \mathrm{~mm}$ & $13.2 \mathrm{~ms}$ & $29.5 \mathrm{~m} / \mathrm{s}$ & \\
\hline Popfossa & $1.02 \mathrm{~m}$ & $2.250 \mathrm{mV}$ & $3.018 \mathrm{mVm}$ & & & & & \\
\hline \multicolumn{9}{|l|}{ Peroncal, R } \\
\hline Ankle & $6.46 \mathrm{~ms}$ & \begin{tabular}{|l|}
$4.050 \mathrm{mV}$ \\
\end{tabular} & $12.87 \mathrm{mVm}$ & Ankle - Fibneck & $280 \mathrm{~mm}$ & $6.84 \mathrm{~ms}$ & $40.9 \mathrm{~m} / \mathrm{s}$ & \\
\hline Fibneck & $13.30 \mathrm{~ms}$ & $3.430 \mathrm{mV}$ & $6.403 \mathrm{mVm}$ & Fibneck - Fibneck & $70 \mathrm{~mm}$ & $1.76 \mathrm{~ms}$ & $39.8 \mathrm{~m} / \mathrm{s}$ & \\
\hline Fibneck & $15.06 \mathrm{~m}$ & $3.400 \mathrm{mV}$ & $4.881 \mathrm{mVm}$ & & & & & \\
\hline \multicolumn{9}{|l|}{ Tibial, $\mathbf{R}$} \\
\hline Ankle & $5.10 \mathrm{~ms}$ & $4.880 \mathrm{mV}$ & $10.64 \mathrm{mVm}$ & Ankle - Popfossa & $380 \mathrm{~mm}$ & $13 \ldots \mathrm{sms}$ & $28.4 \mathrm{~m} / \mathrm{s}$ & \\
\hline Popfossa & $18.48 \mathrm{~ms}$ & $480.0 \mathrm{uV}$ & $1.788 \mathrm{mVm}$ & & & & & \\
\hline
\end{tabular}

Sensory Nerve Conduction Study

\begin{tabular}{|c|c|c|c|c|c|c|c|c|}
\hline Site & \begin{tabular}{|c|}
$\begin{array}{c}\text { Latency } \\
\text { (ms) }\end{array}$ \\
\end{tabular} & Amplitude & Area & Segment & \begin{tabular}{|c|} 
Distance \\
$(\mathrm{mm})$
\end{tabular} & $\begin{array}{c}\text { Interval } \\
\text { (ms) }\end{array}$ & $\begin{array}{l}\mathrm{NCV} \\
(\mathrm{m} / \mathrm{s})\end{array}$ & NCV N.D. \\
\hline \multicolumn{9}{|l|}{ Sural, L } \\
\hline calf & $2.84 \mathrm{~ms}$ & \begin{tabular}{|l|}
$15.00 \mathrm{uV}$ \\
\end{tabular} & $51.97 \mathrm{uVn}$ & & $150 \mathrm{~mm}$ & $2.84 \mathrm{~ms}$ & $52.8 \mathrm{~m} / \mathrm{s}$ & \\
\hline \multicolumn{9}{|l|}{ Sural, $\mathbf{R}$} \\
\hline calf & $2.34 \mathrm{~ms}$ & $9.000 \mathrm{uV}$ & $3.366 \mathrm{uVn}$ & & $150 \mathrm{~mm}$ & $2.34 \mathrm{~ms}$ & $64.1 \mathrm{~m} / \mathrm{s}$ & \\
\hline
\end{tabular}

F-wave Study

\begin{tabular}{|l|c|l|c|l|l|}
\hline Nerve & Tibial & Side & Left & & \\
\hline Stim. Site & Ankle & Rec. Site & AHB & Distance & \\
\hline M-Latency & $7.5 \mathrm{~ms}$ & M-Amplitude & $2.90 \mathrm{mV}$ & F-Occurrence & $6 / 16,37 \%$ \\
\hline
\end{tabular}

\begin{tabular}{|l|c|c|c|c|}
\hline & Mean & S.D. & Min. & Max. \\
\hline F-Latency & $22.63 \mathrm{~ms}$ & $1.99 \mathrm{~ms}$ & $20.05 \mathrm{~ms}$ & $24.50 \mathrm{~ms}$ \\
\hline FWCV & & & & \\
\hline
\end{tabular}

Fig. 1. NCS findings of the patient revealed acute inflammatory demyelinating polyneuropathy (slowing of nerve conduction along the distribution tibial and peroneal nerve of both lower limbs). NCS, nerve conduction study.

\section{Discussion}

Neurological presentations are common in COVID-19 infection. A retrospective case series of 214 patients in China revealed that approximately $36.4 \%$ of patients had neurological manifestations commonly in the form of headache and loss of smell and taste [3,9]. Bangladesh still lacks good quality clinico-epidemiological studies. In an online survey in Bangladesh, the patterns of neurological presentations were $(19.4 \%)$, altered smell $(7.3 \%)$, and altered level of consciousness (0.5\%) [10-12]. Peripheral neuropathy is an infrequent presentation of COVID-19. The exact mechanism of the development of GBS is still poorly understood. So far, most of the reported GBS cases in COVID-19 divulged a progressive limb weakness as the initial presentation. Only 2 cases were reported as a typical post-infectious presentation, such as GBS following Campylobacter infection [13]. In this case, it is unclear whether it is a post-infectious GBS or an initial indication of reinfection. However, the presence of anti-SARS-CoV-2 IgG antibodies in CSF favours a delayed presentation of GBS following the infection. The case responded well to IVIG therapy which reinforces the similar outcome for half of the reported cases of GBS who received IVIG [13]. This case upraises a plausible relation between GBS and COVID-19. The fundamental mechanisms of development of peripheral neuropathy are yet to be explored, though the autoimmune demyelination of peripheral nerves is thought to play as the underlying pathology [14]. 
Table 1. Haematological and biochemical parameters of the patient after admission

$\mathrm{CBC}$

CSF examination

$\begin{array}{ll}\text { S. LDH } & 318 \mathrm{U} / \mathrm{L} \\ \text { S. ferritin } & 135 \mathrm{ng} / \mathrm{mL} \\ \text { S. creatinine } & 1.16 \mathrm{mg} / \mathrm{dL} \\ \text { CRP } & 8 \mathrm{mg} / \mathrm{dL}\end{array}$

COVID-19 antibody (serum)

$(\operatorname{Ig} M+\operatorname{IgG})$

Hb $13.9 \mathrm{~g} / \mathrm{dL}$

Positive
WBC $8 \times 10^{3}, \mathrm{~N} 73 \%$, L $22 \%$, M $4 \%$, platelet count $178 \times 10^{3}$

Physical examination: volume $0.5 \mathrm{~mL}$, colour: watery, appearance: clear

Microscopic examination: total cell count (WBC), 02 cells $/ \mathrm{mm}^{3}$.

Morphology: all are lymphocytes, RBC: few/HPF.

Biochemistry: glucose $5.2 \mathrm{mmol} / \mathrm{L}$, protein $0.93 \mathrm{~g} / \mathrm{L}$, chloride $113 \mathrm{mmol} / \mathrm{L}$ COVID-19 antibody test (CSF): IgM positive, IgG positive

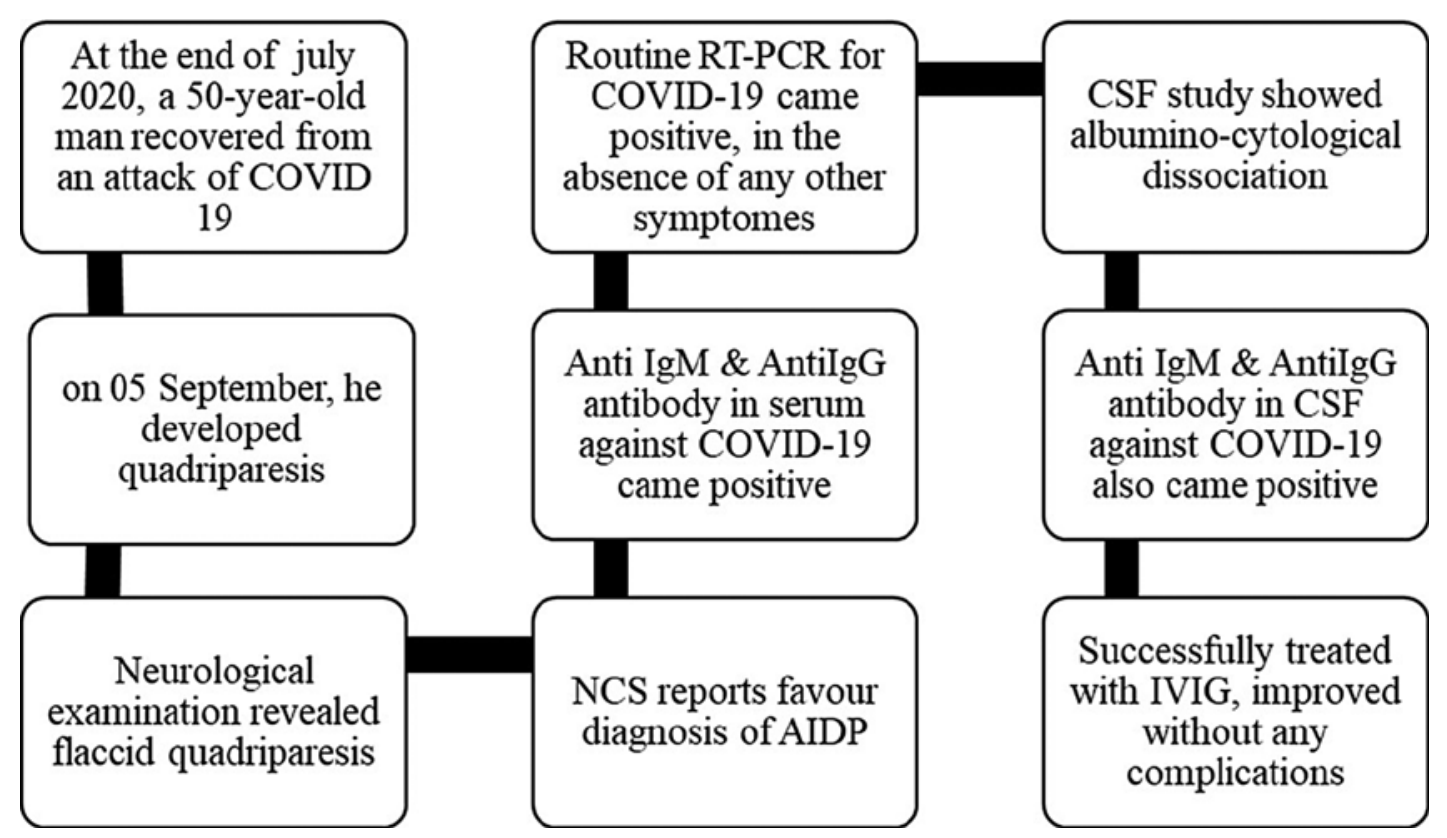

Fig. 2. The timeline of major events during management of the case.

Neurological presentations are underreported and, on many occasions, remain unrecognised in resource-limited settings. Bangladesh is known to have one of the highest number of GBS cases worldwide before the pandemic, although this probably is the first case reported during this pandemic [15]. The present case will hopefully emphasize the importance of neurological surveillance and strong reporting system from our hospitals. This case report demands extensive clinico-epidemiological studies, primarily focusing on finding neurological clinical features of COVID-19, which will further guide us in detecting suspected cases with neurological symptoms as an initial presentation. A substantial portion of long neurological COVIDs requires a comprehensive rehabilitation plan. We recommend a well-planned follow-up protocol for the neuro-COVIDs to address their issues in a better way. 


\section{Acknowledgment}

We thank Dr. S.M. Rashedul Islam, Assistant Professor of Virology Department, BSMMU, for doing the RT-PCR for SARS-CoV-2 on CSF.

\section{Statement of Ethics}

Informed written consent was obtained from the patient for publication of this case report and accompanying image. "The study is exempt from ethics committee approval," because this study includes data of only 1 patient. For publishing a case report, approval from the ethics committee is not required in our institute.

\section{Conflict of Interest Statement}

The authors declare that they have no known competing financial interests or personal relationships that could have appeared to influence the work reported in this study.

\section{Funding Sources}

No funding was secured for this case report.

\section{Author Contributions}

F.U.H.C., S.A., M.R., and M.M.R. made the diagnosis of the case and were involved with direct clinical management. A.H. and F.R.C. provided the necessary laboratory support to confirm the diagnosis. S.P., F.U.H.C., and F.R.C. wrote the primary draft of the manuscript. All authors revised the draft and agreed upon the final version of the article.

\section{Data Availability Statement}

All data generated or analysed during this study are included in this article. Further enquiries can be directed to the corresponding author.

\section{References}

1 World Health Organization. Coronavirus disease 2019 (COVID-19) dashboard: Bangladesh situation [Internet]. [cited 2021 May 30]. Available from: https://covid19.who.int/region/searo/country/bd.

2 Li Q, Guan X, Wu P, Wang X, Zhou L, Tong Y, et al. Early transmission dynamics in Wuhan, China, of novel coronavirus-infected pneumonia. N Engl J Med. 2020 Jan 29;382(13):1199-207.

3 Mao L, Jin H, Wang M, Hu Y, Chen S, He Q, et al. Neurologic manifestations of hospitalized patients with coronavirus disease 2019 in Wuhan, China. JAMA Neurol. 2020 Jun 1;77(6):683-90.

4 Helms J, Kremer S, Meziani F, Clere-Jehl R, Schenck M, Kummerlen C, et al. Neurologic features in severe SARSCoV-2 infection. N Engl J Med. 2020 Apr 15;382(23):2268-70.

5 Montalvan V, Lee J, Bueso T, De Toledo J, Rivas K. Neurological manifestations of COVID-19 and other coronavirus infections: a systematic review. Clin Neurol Neurosurg. 2020 Jul;194:105921.

6 van den Berg B, Walgaard C, Drenthen J, Fokke C, Jacobs BC, van Doorn PA. Guillain-Barré syndrome: pathogenesis, diagnosis, treatment and prognosis. Nat Rev Neurol. 2014;10(8):469-82. 
7 Caress JB, Castoro RJ, Simmons Z, Scelsa SN, Lewis RA, Ahlawat A, et al. COVID-19-associated Guillain-Barré syndrome: the early pandemic experience. Muscle Nerve. 2020 Oct;62:485-91.

8 Sheikh AB, Chourasia PK, Javed N, Chourasia MK, Suriya SS, Upadhyay S, et al. Association of Guillain-Barre syndrome with COVID-19 infection: an updated systematic review. J Neuroimmunol. 2021 Jun;355:577577.

9 Ellul MA, Benjamin L, Singh B, Lant S, Michael BD, Easton A, et al. Neurological associations of COVID-19. Lancet Neurol. 2020 Sep 1;19(9):767-83.

10 Hasan MJ, Chowdhury SM, Khan MAS, Rahaman M, Fardous J, Adit T, et al. Clinico-epidemiological characteristics of asymptomatic and symptomatic COVID-19-positive patients in Bangladesh. medRxiv. 2020 Jan 1. http: //medrxiv.org/content/early/2020/08/21/2020.08.18.20177089.abstract.

11 Hussain ME, Hoque MA, Alam MB, Yusuf MA, Chowdhury RN, Mohammad QD. Neurological manifestations of COVID-19 patients: an updated review and observations of COVID patients in the National Institute of Neurosciences and Hospital, Dhaka, Bangladesh. J Bangladesh Coll Physicians Surg. 2020;38:122-32.

12 Mohammad QD, Hussain ME. Neurological manifestations in COVID-19 patients: Bangladesh perspective. J Natl Inst Neurosci Bangladesh. 2020;6(2):72-3.

13 Zito A, Alfonsi E, Franciotta D, Todisco M, Gastaldi M, Cotta Ramusino M, et al. COVID-19 and Guillain-Barré syndrome: a case report and review of literature. Front Neurol. 2020;11:1-7.

14 Alberti P, Beretta S, Piatti M, Karantzoulis A, Piatti ML, Santoro P, et al. Guillain-Barré syndrome related to COVID-19 infection. Neurol Neuroimmunol Neuroinflamm. 2020 Jul;7(7).

15 Uncini A, Vallat J-M, Jacobs BC. Guillain-Barré syndrome in SARS-CoV-2 infection: an instant systematic review of the first six months of pandemic. J Neurol Neurosurg Psychiatry. 2020;91(10):1105-10. https://jnnp.bmj. com/content/91/10/1105. 